\title{
Diagnosis of Paratuberculosis by Fecal Culture Followed by Nested-Polymerase Chain Reaction
}

\author{
Anand Mohan*, P. Das and N. Kushwaha \\ Biological Product Division, Indian Veterinary Research Institute, Izatnagar, India \\ *Corresponding author
}

\begin{abstract}
A B S T R A C T
Culture of clinical samples is the confirmatory test for the diagnosis of paratuberculosis but, it is time consuming due to its long incubation period, further it requires a skilled personnel to monitor the growth. Use of molecular techniques such as PCR is advantageous over the long incubation period in culturing of samples; more than eight months of incubation is needed to declare a sample to be negative. Two cattle farms (Cattle rehabilitation center and organized dairy farm) with different organizational setup were screened by culture of fecal samples. Ziehl-Neelsen (ZN) staining and nested-PCR were implied to confirm the growths on these samples after two months of inoculation on Herrold's Egg Yolk Medium (HYM). Overall, 33.67\% samples confirmed the growth of Map bacilli and $25.00 \%$ samples confirmed the growth of acid-fast bacilli. In cattle rehabilitation center $50.00 \%$ samples confirmed the growth of Map bacilli and $35.63 \%$ shown to have acid-fast bacilli, whereas in the organized dairy farm it was $15.00 \%$ and $13.57 \%$, respectively. Confirmation of growth of bacilli in samples belongs to age groups $0-<3$ yrs and $3-<6$ yrs were indicated, approximately same level of infection $\left(\chi^{2}\right.$; $\mathrm{p}>0.05)$, but significantly higher level of infection were confirmed in age group of $\geq 6$ yrs $\left(\chi^{2} ; p<0.05\right)$. Appreciable colonies were identified after the incubation of 7 to 9 months on cultures positive in both $\mathrm{ZN}$ stain and nested-PCR, but cultures negative in nested-PCR were failed to produce colonies even after incubation of one year. Study confirmed that variation in level of paratuberculosis in these two cattle farm with possible organizational set up influences. Present study concludes that, use of nested-PCR in conjunction with fecal culture reduce long incubation period to confirm Map bacilli and high percentage of paratuberculosis positive animals in old age group in both farms.
\end{abstract}

\section{Introduction}

Mycobacterium avium subspecies paratuberculosis (Map) causes chronic, granulomatous enteritis of ruminants, known as paratuberculosis or Johne's disease. Host acquires infection in early life via feco-oral route through the ingestion of contaminated colostrums, milk, water, or feed (Sweeney, 1996) and also possibly through intrauterine route (Seitz et al., 1989). Disease can persist for several years in a subclinical phase without showing any clinical signs. However, once the disease enters the clinical phase, the wall of intestine get thickened which leads to diarrhea, weight loss, decreased milk 
production and eventual death (Hasonova and Pavlik, 2006). Disease can be diagnosed by detection of viable bacilli (culture), genome (PCR), host immune response (Harris and Barletta, 2001), etc. Antibody detection techniques such as enzyme-linked immunosorbent assay (ELISA) are commonly used diagnostics (Collins et al., 2005). However, host humoral immune response to bacilli is delayed and techniques which rely on humoral response are to be used in advanced stage of infection. Meantime, infected animals may contaminate the environment or pass infection to other susceptible animals. Culture of Map is considered as gold standard and confirmatory diagnosis of paratuberculosis, but is time consuming and requires 8 to 16 weeks of incubation. The application of molecular techniques in conjunction with culture may hasten the diagnostic procedure. PCR is most common and widely used molecular technique and has been adopted in different format. PCR using insertion sequence IS900 has been routinely used to detect the Map genome but, similarities with other mycobacterium, particularly Maa (97\% DNA homology) decreases its specificity. Furthermore, sequences related to IS900 have also been identified in Wood pigeon mycobacterium (IS902), $M$. intracellulare (IS1626) and Maa (IS901 and IS1626). Therefore a positive IS900 should be confirmed by subsequent nested-PCR or by a PCR assay targeting another gene or sequence in Map genome.

Present study was designed to investigate the level of infection in two different cattle population with culture followed by $\mathrm{ZN}$ staining and nested-PCR for confirmation of disease. IS 900 and $f 57$ sequences have been used as complementary to each other in nested format to ascertain the Map bacilli. Results were also being compared with test Nested-PCR and ZN staining which was performed before culture of samples on HYM.

\section{Materials and Methods}

\section{Animal population and sample collection}

Fecal samples were collected directly from rectum of animals and kept in plastic bag; a cold chain was maintained till the samples were processed. Two cattle farms were chosen; one was unproductive cattle rehabilitation center i.e. Gaushala (Barsana, Mathura, Uttar Pradesh) which maintains unproductive, orphan, discarded animals. A total of 160 sick cattle with the history of chronic diarrhea and ill health, were selected for sample collection. Another was instructional cattle dairy farm, Pantnagar (Uttarakhand), maintains the animals for milk production. Here samples were collected from 140 cattle without given preference to sick animals. Details of fecal samples collected with respect to age are mentioned in table 1.

\section{Processing and Culture of fecal samples}

Fecal samples were decontaminated in $0.75 \%$ (W/V) Hexadecylpyridium chloride (HPC) to remove contaminant microorganism (OIE Terrestrial Manual, 2008). Decontaminated sediment $(100 \mu \mathrm{l})$ was inoculated on Herrold's Egg Yolk Medium (HYM) containing mycobactin-J (2 $\mu \mathrm{g} / \mathrm{ml})$ in duplicates. HYM was prepared according to the composition mentioned in OIE Terrestrial manual (2008) and was modified with addition of chloramphenicol $(50 \mu \mathrm{g} / \mathrm{ml})$, penicillin $(100 \mathrm{U} / \mathrm{ml})$ and amphotericin-B (50 $\mu \mathrm{g} / \mathrm{ml})$. The slants were incubated at $37^{\circ} \mathrm{C}$ at least for 4 months with regular observation. Any visible growth was confirmed by $\mathrm{ZN}$ staining, followed by nested-PCR. Slants which did not give positive results with PCR even after four month of incubation declared Map negative, but observed up to 1 year. 


\section{Confirmation of Map by nested-PCR}

Slants with suspected growth of $\geq 2$ months old were taken for genomic DNA isolation as well as $\mathrm{ZN}$ staining. Methods described by Kauppinen et al., (1994) were followed with suitable modifications for DNA isolation. Confirmation of Map bacilli was done based on presence of IS900 and $f 57$ sequence. Primer pairs, PCR reaction compositions, thermocyclic and electrophoretic conditions were followed as prescribed by Vansnick et al., (2004). Briefly, all samples were screened for IS900 insertion sequence which corresponds to 572bp amplicon. Positive amplicons were again amplified with different internal primer pair which corresponds to 452bp amplicons (Nested-PCR). Samples which were positive in both amplification of IS900 were again screened for presence of $f 57$ sequence in same way as IS900. Amplicons of $432 \mathrm{bp}$ and $424 \mathrm{bp}$ respectively in first and second amplification for $f 57$ sequence were expected in positive cases. Samples which had given all four amplicons of IS900 and f57 were designated as positive otherwise declared negative for Map.

\section{Results and Discussion}

Cultures of fecal samples were weekly monitored for any growth and contaminations. As contamination was the main complication (Nielsen et al., 2004) in the initial few weeks of incubation but it was resolved by subculture to new slant. Contamination requires more attention since tubes need to be incubated for longer duration. Typical colonial morphology of Map is difficult to identify particularly in primary isolation, however small (1 $\mathrm{mm}$ diameter), colorless, translucent, hemispherical, smooth and glistening colony would be expected after 8 weeks of growth (Sevilla et al., 2007). Most of tubes didn't show any appreciable growth at two month of incubation. Slow growth of Map in primary culture and adaptation on artificial media retard its multiplication. More than $25 \mathrm{hrs}$ (Thorel et al., 1990) is required to complete a multiplication cycle, even though 1.2 days to 10 days generation time have also been estimated (Elguezabal et al., 2011). Some of tubes had minute transparent colonies after the incubation of 7 to 9 months (Figure 1A and 1B). Standard laboratory working on Map suggests; colonies are appreciable any time after 5 weeks to 6 months of incubation (Gwozdz, 2010) in primary isolation and recommends negative samples should not be discarded without incubation of 6 to 8 months (de Juan et al., 2006). Further, monitoring of growth should be regular after 4 weeks of incubation (Whipple et al., 1991). ZN stain suggested growth of concern bacilli was undergoing even they were not appreciated on naked eye (Figure 2).

All tubes were screened by nested-PCR after two month of inoculation. Primer pairs correspond to IS900 and f57 sequences separately were used in nested manner (Vansnick et al., 2004). Preliminary screening by ZN staining shown $25.00 \%$ samples together from both farms had growth of acidfast bacilli (Table 1). However, confirmation based on presence of IS900 and $f 57$ sequences (Figure 3) in nested-PCR revealed $33.67 \%$ samples had Map bacilli. In individual farms, acid-fast positive culture was $35.63 \%$ and $13.57 \%$, respectively, in cattle rehabilitation center and dairy farm. Confirmed cases of Map in both farms were $50.00 \%$ and $15.00 \%$, respectively (Table 1). Although, level of paratuberculosis in the places from where these samples were collected, was 20 to $30 \%$ (Mishra et al., 2009; Singh et al., 2010; Singh et al., 2013). The way of sampling, particularly from cattle rehabilitation center was supposed to be the causal factor of high level of paratuberculosis diagnosed. Farm crowded with aged, discarded, apparently 
healthy and diseased animals make the ground for high level of paratuberculosis in cattle rehabilitation center. Crowding of animals in small premises had also built the ground for easy and rapid transmission of infection among susceptible hosts. Continuous mixing of old and new animals in farm might hasten the rate of infection. In addition, nested-PCR is sensitive and specific technique (Herthnek and Bolske, 2006; Wells et al., 2006: Douarre et al., 2010) and hence able to confirm the growth of bacilli on culture which was incubated for $\geq 2$ months. Sub-normal level of bacilli may be enriched during incubation of two months and might be diagnosed as positive both in $\mathrm{zn}$ staining and nested PCR. In contrary, organized dairy farm had comparatively low level of infection; it may be attributed to method of sample collection (not biased toward the sick animals) and organizational setup of the farm.

Growths confirmed by ZN staining/NestedPCR in age groups $0-<3$ yrs and $3-<6$ yrs (Table 1) had approximately same level of infection $\left(\chi^{2} ; p>0.05\right)$. This might be due to small sample size. However, level of paratuberculosis in advanced age group $(\geq 6$ yrs) was high $\left(\chi^{2} ; \mathrm{p}<0.05\right)$. Similar conclusion has also been given by Nielsen et al., (2013). This could be explained as infection build up in animals was cumulative due to long incubation and was diagnosed only after animals excrete bacilli in feces (Crossley et al., 2005) or immune system response to bacilli and both occur late in case of paratuberculosis.

Table.1 Number of positive cases from two cattle farm with respect to age in different diagnostics on fecal samples for paratuberculosis. *Cattle rehabilitation center (Goshala, Barsana, Mathura, Utter Predesh); ${ }^{* *}$ Instructional cattle dairy farm (Pantnagar, Uttarkhand); ${ }^{\text {a Samples }}$ grown on HYM and stained after a fixed incubation period; ${ }^{b} \mathrm{PCR}$ was performed on culture grown on HYM; P- No. of positive samples; T-Samples tested. Figure in parentheses indicate percentage

\begin{tabular}{|c|c|c|c|c|c|c|}
\hline \multirow[t]{2}{*}{ Age } & \multicolumn{2}{|c|}{ Unorganized farm* } & \multicolumn{2}{|c|}{ Organized dairy farm ${ }^{* *}$} & \multicolumn{2}{|c|}{ Grand total } \\
\hline & $\mathrm{P}(\%)$ & $\mathrm{T}$ & $\mathrm{P}(\%)$ & $\mathrm{T}$ & $\mathrm{P}(\%)$ & $\mathrm{T}$ \\
\hline \multicolumn{7}{|c|}{ ZN Staining ${ }^{\mathbf{a}}$} \\
\hline $0-<3$ yrs & $10(41.67)$ & 24 & $2(12.50)$ & 16 & $12(30.00)$ & 40 \\
\hline $3-<6$ yrs & $8(36.36)$ & 22 & $9(15.25)$ & 59 & 17 (20.99) & 81 \\
\hline$\geq 6 \mathrm{yrs}$ & $39(34.21)$ & 114 & $8(12.31)$ & 65 & $47(26.26)$ & 179 \\
\hline Sub-total & $57(35.63)$ & 160 & $19(13.57)$ & 140 & $75(25.00)$ & 300 \\
\hline \multicolumn{7}{|c|}{ Nested PCR } \\
\hline $0-<3$ yrs & $15(62.50)$ & 24 & $2(12.50)$ & 16 & $17(42.50)$ & 40 \\
\hline $3-<6$ yrs & $12(54.55)$ & 22 & $8(13.56)$ & 59 & $20(24.69)$ & 81 \\
\hline$\geq 6 \mathrm{yrs}$ & $53(46.49)$ & 114 & $11(16.92)$ & 65 & $64(35.75)$ & 179 \\
\hline Sub-total & $80(50.00)$ & 160 & $21(15.00)$ & 140 & $101(33.67)$ & 300 \\
\hline
\end{tabular}


Figure.1 Growth of Map on HYM after A: 7 months and B: 9 months of incubation.

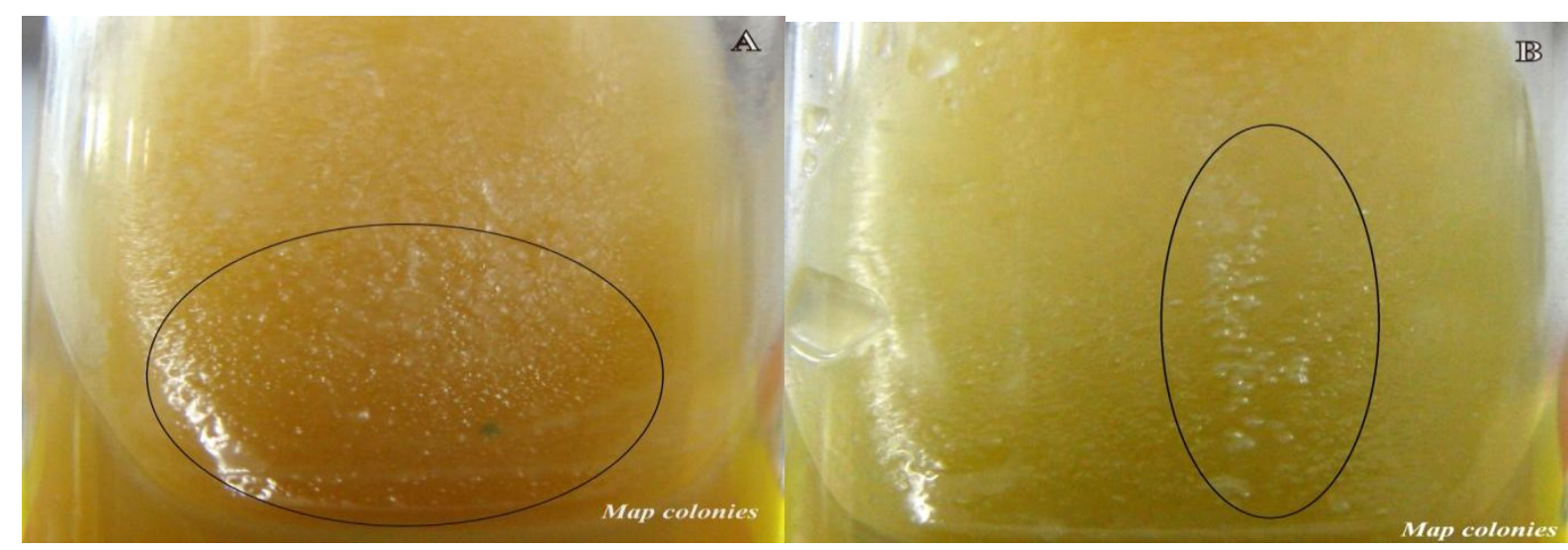

Figure.2 ZN stained bacilli which was incubated $\geq 2$ months on HYM

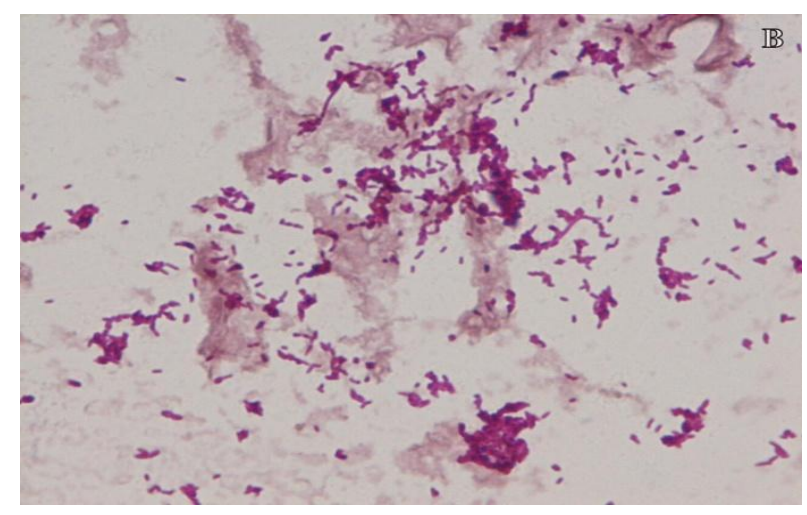

Figure.3 Amplicons of A: IS 900 and B: $f 57$ sequences of Map from samples which was incubated $\geq 2$ months on HYM

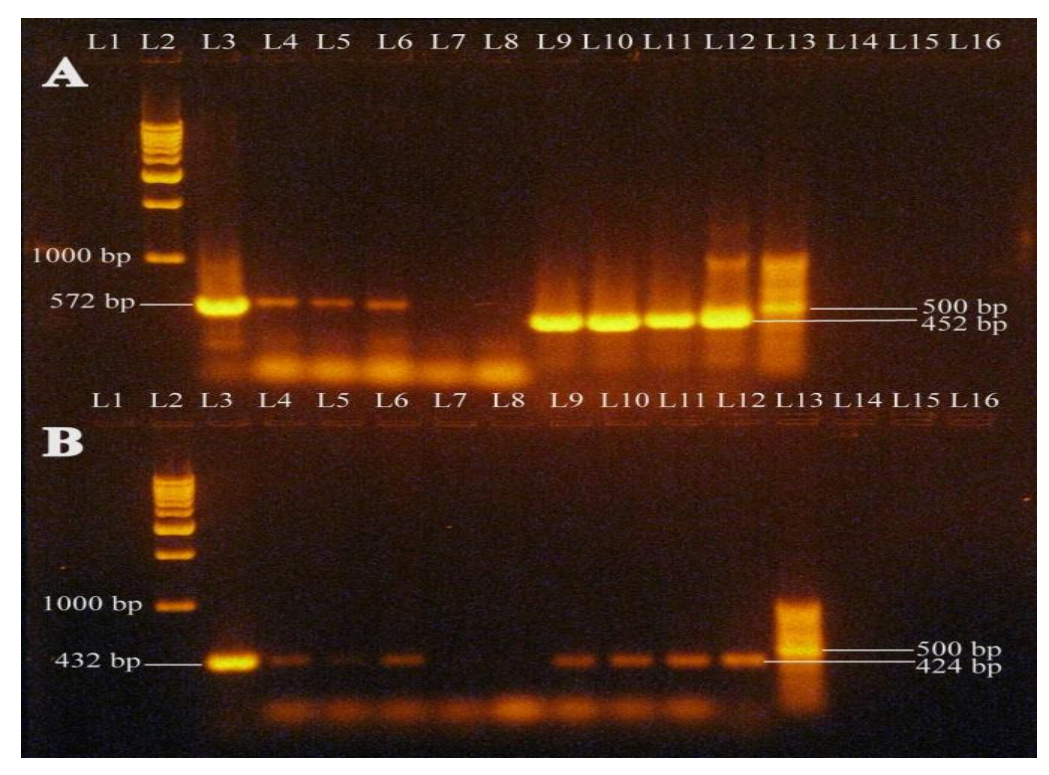


Nested-PCR with same primer pairs and ZN staining has also been performed on fecal samples (Mohan et al., 2013), but percentage of positive samples diagnosed was low. Several reasons could be postulated; one of them was the organic matters of feces, which could be interfered in DNA isolation, some of them were identified as polymerase inhibitor (Widjojoatmodjo et al., 1992). Host might excrete sub-optimal level, erratic shedding of bacilli; particularly in earlier stage of disease. Decontamination procedure also reduced the viable bacilli in clinical samples (Reddacliff et al., 2003) significantly. Taking these in consideration, culture was performed on HYM, from decontaminated fecal samples. A considerable number of negative samples in each age group of animals from both farms were diagnosed positive in respective tests (Nested-PCR and ZN staining). Culture of clinical samples is always confirmatory to disease. In case of paratuberculosis, fecal culture is routinely used and found superior to other tests, even though it helps in calculating the diagnostic efficiency of different techniques (Martinson et al., 2008; Sharma et al., 2008; Douarre et al., 2010; Sonawane and Tripathi, 2013).

Present study concludes that nested-PCR (IS900 and f57) used in conjunction with fecal culture can be used to reduce the need of long incubation for culture of samples on HYM. Different organizational setup of farms might be responsible for unusual level of paratuberculosis diagnosed particularly in cattle rehabilitation center but high percentage of paratuberculosis positive animals in old age group in both farms.

\section{Acknowledgements}

We are thankful to Dr. Ranbir Singh, Senior Scientist, Animal Genetics Division, Indian Veterinary Research Institute, Izatnagar-243 122 for helping in sample collection and
University Grant Commission/Indian Council of Agricultural Research, New Delhi for providing funds needed to carry out this work successfully.

\section{References}

Collins, M. T., Wells, S. J., Petrini, K. R., Collins, J. E., Schultz, R. D. and Whitlock, R. H. 2005. Evaluation of five antibody detection tests for diagnosis of bovine paratuberculosis. Clinical and Diagnostic Laboratory Immunology. 12: 685-692.

Crossley, B. M., Zagmutt-Vergara, F. J., Fyock, T. L., Whitlock, R. H. and Gardner, I. A. 2005. Fecal shedding of Mycobacterium avium subsp. paratuberculosis by dairy cows. Veterinary Microbiology. 107: 257263.

de Juan, L., Alvarez, J., Romero, B., Bezos, J., Castellanos, E., Aranaz, A., Mateos, A. and Domínguez, L. 2006. Comparison of four different culture media for isolation and growth of type II and type I/III Mycobacterium avium subsp. paratuberculosis strains isolated from cattle and goats. Applied and Environmental Microbiology. 72: 59275932.

Douarre, P. E., Cashman, W., Buckley, J., Coffey, A. and O'Mahony, J. M. 2010. Isolation and detection of Mycobacterium avium subsp. paratuberculosis from cattle in Ireland using both traditional culture and molecular based methods. Gut Pathogens. 2: 11. doi: 10.1186/17574749-2-11.

Elguezabal, N., Bastida, F., Sevilla, I. A., Gonzalez, N., Molina, E., Garrido, J. M. and Juste, R. A. 2011. Estimation of Mycobacterium avium subsp. paratuberculosis Growth Parameters: Strain Characterization and Comparison of Methods. Applied and Environmental Microbiology. 77: 8615-8624.

Gwozdz, J. M. 2010. Johne's disease. In: OIE and National Reference Laboratory for 
Johne's Disease, Australia. SubCommittee on Animal Health Laboratory Standards.

http://www.scahls.org.au/Procedures/Doc uments/ANZSDP/Johnes_Disease_ANZS DP_2010.pdf

Harris, L. P. and Barletta, R. G. 2001. Mycobacterium avium subsp.

Paratuberculosis in veterinary medicine. Clinical Microbiology Reviews. 14: 489512.

Hasonova, L. and Pavlik, I. 2006. Economic impact of paratuberculosis in dairy cattle herds: a review. Veterinarni Medicina. 51: 193-211.

Herthnek, D. and Bölske, G. 2006. New PCR systems to confirm real-time PCR detection of Mycobacterium avium subsp. paratuberculosis. BMC Microbiology 6: 87. doi: 10.1186/1471-2180-6-87.

Kauppinen, J., Pelkonen, J. and Katila, M. L. 1994. RFLP analysis of Mycobacterium malmoense strains using ribosomal RNA gene probes: an additional tool to examine intra species variation. Journal of Microbiological Methods. 19: 261-267.

Martinson, S. A., Hanna, P. E., Ikede, B. O., Lewis, J. P., Miller, L. M., Keefe, G. P. and McKenna, S. L. B. 2008. Comparison of bacterial culture, histopathology, and immunohistochemistry for the diagnosis of Johne's disease in culled dairy cows. Journal of Veterinary Diagnostic Investigation. 20: 51-57.

Mishra, P., Singh, S. V., Bhatiya, A. K., Singh, P. K., Singh, A. V. and Sohal, J. S. 2009. Prevalence of bovine Johne's disease (BJD) and Mycobacterium avium Subspecies paratuberculosis genotypes in dairy cattle herds of Mathura district. Indian Journal of Comparative Microbiology Immunology and Infectious Disease. 30: 23-25.

Mohan, A., Das, P., Kushwaha, N., Karthik, K. and Niranjan, A. K. 2013. Investigation on the status of Johne's disease based on agar gel immunodiffusion, Ziehl-Neelsen staining and nested PCR approach in two cattle farm. Veterinary World. 6: 778-
784.

Nielsen, S. S., Kolmos, B. and Christoffersen, A. B. 2004. Comparison of contamination and growth of Mycobacterium avium subsp. paratuberculosis on two different media. Journal of Applied Microbiology. 96: 149-153.

Nielsen, S. S., Toft, N. and Okura, H. 2013. Dynamics of Specific AntiMycobacterium avium Subsp. paratuberculosis Antibody Response through Age. PLoS One. 8: e63009. doi:10.1371/journal.pone.0063009

Office International Epizootics (OIE). 2008. Paratuberculosis (Johne's disease). Terrestrial Manual, Chapter 2.1.11. 276291.

Reddacliff, L. A., Vadali, A. and Whittington, R. J. 2003. The effect of decontamination protocols on the numbers of sheep strain Mycobacterium avium subsp. paratuberculosis isolated from tissues and faeces. Veterinary Microbiology. 95: 271282.

Seitz, S. E., Heider, L. E., Heuston, W. D., Bech-Nielsen, S., Rings, D. M. and Spangler, L. 1989. Bovine fetal infection with Mycobacterium paratuberculosis. Journal of the American Veterinary Medical Association. 194: 1423-1426.

Sevilla, I., Garrido, J. M., Geijo, M. and Juste, R. A. 2007. Pulsed-field gel electrophoresis profile homogeneity of Mycobacterium avium subsp. paratuberculosis isolates from cattle and heterogeneity of those from sheep and goats. BMC Microbiology. 7: 18. doi: 10.1186/1471-2180-7-18.

Sharma, G., Singh, S. V., Sevilla, I., Singh, A. V., Whittington, R. J., Juste, R. A., Kumar, S., Gupta, V. K., Singh, P. K., Sohal, J. S. and Vihan, V. S. 2008. Evaluation of indigenous milk ELISA with $\mathrm{m}$-culture and $\mathrm{m}$-PCR for the diagnosis of Bovine Johne's disease (BJD) in lactating Indian dairy cattle. Research in Veterinary Science. 84: 3037.

Singh, A. V., Singh, S. V., Singh, P. K., Sohal, 
J. S. and Mahour, K. 2010. Serosurveillance of Mycobacterium avium Subspecies Paratuberculosis Infection in domestic livestock in North India using indigenous absorbed ELISA test. Journal of Advanced Laboratory Research in Biology. 1: 1-4. ISSN 0976-7614.

Singh, S. V., Kumar, N., Chaubey, K. K., Gupta, S. and Rawat, K. D. 2013. Biopresence of Mycobacterium avium subspecies paratuberculosis infection in Indian livestock farms. Research Opinions in Animal and Veterinary Sciences. 3: 401-106

Sonawane, G. G. and Tripathi, B. N. 2013. Comparison of a quantitative real-time polymerase chain reaction (qPCR) with conventional PCR, bacterial culture and ELISA for detection of Mycobacterium avium subsp. paratuberculosis infection in sheep showing pathology of Johne's disease. Spinger plus. 2: 45. doi: 10.1186/2193-1801-2-45.

Sweeney, R. W. 1996. Transmission of paratuberculosis. Veterinary Clinics of North America: Food Animal Practice. 12: 305-312.

Thorel, M. F., Krichevsky, M. and LevyFrebault, V. V. 1990. Numerical taxonomy of mycobactin-dependent mycobacteria, emended description of Mycobacterium avium, and description of Mycobacterium avium subsp. avium subsp. nov., Mycobacterium avium subsp. paratuberculosis subsp. nov., and Mycobacterium avium subsp. silvaticum subsp. nov. International Journal of Systemic Bacteriology. 40: 254-260.

Vansnick, E., de Rijk, P., Vercammen, F., Geysen, D., Rigouts, L., Portaels, F. 2004. Newly developed primers for the detection of Mycobacterium avium subspecies paratuberculosis. Veterinary Microbiology. 100: 197-204.

Wells, S. J., Collins, M. T., Faaberg, K. S., Wees, C., Tavornpanich, S., Petrini, K. R., Collins, J. E., Cernicchiaro, N. and Whitlock, R. H. 2006. Evaluation of a Rapid Fecal PCR Test for Detection of Mycobacterium avium subsp. paratuberculosis in Dairy Cattle. Clinical and Vaccine Immunology. 13: 11251130 .

Widjojoatmodjo, M. N., Fluit, A. C., Torensma, R., Verdonk, G. P. H. T. and Verhoef, J. 1992. The Magnetic Immuno Polymerase Chain Reaction Assay for Direct Detection of Salmonellae in Fecal Samples. Journal of Clinical Microbiology. 30: 3195-3199.

Whipple, D. L., Callihan, D. R. and Jarnagin, J. L. 1991. Cultivation of Mycobacterium paratuberculosis from bovine fecal specimens and a suggested standardized procedure. Journal of Veterinary Diagnostic Investigation. 3: 368-373.

\section{How to cite this article:}

Anand Mohan, P. Das and N. Kushwaha. 2020. Diagnosis of Paratuberculosis by Fecal Culture Followed by Nested-Polymerase Chain Reaction. Int.J.Curr.Microbiol.App.Sci. 9(05): 17311738. doi: https://doi.org/10.20546/ijcmas.2020.905.194 